\title{
Ethics Education for Contemporary Clinical Pharmacy Practice in Nigeria: Shortfalls and Needs
}

\author{
Roland N. Okoro \\ Department of Clinical Pharmacy and Pharmacy Administration, \\ Faculty of Pharmacy, University of Maiduguri, Nigeria, \\ Email: orolandn@gmail.com
}

\begin{abstract}
The past decade has witnessed a shift in the ambitions of pharmacists away from the core role of dispensing medicines towards more interesting and rewarding relationships and responsibilities with other healthcare providers and patients. The patient-centred role of pharmacists has allowed ethical issues experienced in medical practice to surface in pharmacy practice, resulting in an increase in the number and variety of ethical dilemmas that pharmacists face in their routine pharmacy practice. Pharmacy education prepares pharmacy students for practice and must be in tune with the professional dynamics. Many countries that provide patient-centered pharmacy services have redesigned pharmacy ethics education while others are in various stages of revision of their curriculum in order to adequately equip future pharmacists with the rudiments required to handle ethical issues in clinical pharmacy practice. In contrast, in Nigeria, little or no pharmacy ethics is taught to pharmacy students and the challenge lies with the curriculum design and method of teaching.
\end{abstract}

Key words: Curriculum, Ethics Education, Nigeria, Clinical Pharmacy, Patient-centred

Introduction: Pharmacy as a profession has undergone several dramatic changes over recent years. Pharmaceutical care has allowed the ethical issues experienced in medical practice to surface in pharmacy practice $^{1}$. These ethical issues include decisions on choices related to drug therapies, uses of drugs for unapproved indications, patient confidentiality, financial relationships with the drug industry, allocation of scarce resources, pain management, death and dying, and so on ${ }^{2,3}$.

Ethical issues significantly impacts on patients' quality of life; therefore, pharmacists are obliged to utilize ethical principles (autonomy, beneficence, justice, non-maleficence), theories (such as utilitarianism, deontology) and/or codes of ethics when necessary. Disappointedly, many pharmacists are unable to detect, discuss and resolve value and ethical issues in pharmacy practice. Moreover, the increasing collaborative and patient-centred roles of contemporary pharmacists have heightened the need for effective pharmacy ethics education. Hence, pharmacy education curriculum should be adequate to prepare future pharmacists for clinical practice and to teach them skills needed to address ethical challenges that may arise in real-world pharmacy practice ${ }^{4}$.

Current situation of pharmacy ethics education in Nigeria: The Nigerian University Commission (NUC) which is the 
apex regulatory authority of education in Nigeria has described pharmacy ethics in a 2-credit hour forensic pharmacy and pharmacy ethics single course in the just newly approved Doctor of Pharmacy (PharmD) programme ${ }^{5}$. However, the University of Benin PharmD curriculum described pharmacy ethics as a component of a 2-credit unit pharmacy law and ethics single course with same contents as approved by the NUC (Table 1) ${ }^{6}$. Ascertaining what is currently covered in this course will paint a picture of what is being taught and will help to identify needs. Table 1 reveals ethics of pharmacy profession in Nigeria, and ethics and good business practice as the only ethics topics covered in the PharmD programme

\section{Shortfalls of the Nigerian pharmacy} ethics syllabus: The curriculum content and method of teaching affect knowledge, critical thinking and learning skills. To the best of the knowledge of the author, there is still no formal pharmacy ethics syllabus being seriously implemented in Nigerian pharmacy schools for both PharmD and Bachelor of Pharmacy (B. Pharm.) programmes. Though pharmacy ethics exists as a component of forensic pharmacy and pharmacy ethics course in the curriculum, ethics syllabus is very weak, shallow, not well developed, and grossly inadequate for the present-day clinical pharmacy practice. Pharmacy law and ethics single course has traditionally been taught didactically as if it were solely consist of a set of specific rules to be learned and obeyed. Additionally, the combination of pharmacy law and pharmacy ethics as a single course has given room for these deficiencies, and pharmacy law predominance.

In order to reemphasize the professional code of ethics, the Pharmacists Council of Nigeria (PCN) during pre-induction programmes deems it necessary to give pre- induction orientation talk on the code of ethics for pharmacists to about to be inducted pharmacists. Though, knowledge of the code of ethics alone cannot necessarily translate to a commensurate level of ethics knowledge ${ }^{7}$. The implications of the lack of ethics education for clinical pharmacy practice are critical since the absence of internal control provokes external control. In addition, the improvement in pharmacy education in the area of research ethics will go a long way to improve the scope of ethics in clinical pharmacy research. Graduates or even post graduate students as in the case in other climes who find themselves in various Ethics Review Boards will be adequately trained for this role.

Reinventing Nigerian pharmacy ethics education for future pharmacists: According to the guideline of the Accreditation Council for Pharmacy Education (ACPE), "teaching professional behaviour, principles and ethical issues related to the prescription, use of drugs, delivering patient-centred care, performing clinical research, team work, dealing with ethical dilemmas, and conflict of interest among others are essential to the development of pharmacists" ${ }^{8}$. These issues are not covered in the current Nigerian pharmacy ethics syllabus.

Current global best clinical pharmacy practice attaches great importance to the practice ethics, and students need to be educated on various aspects of pharmacy practice ethics. Therefore, some schools and colleges of pharmacy in other climes have developed enriched standalone ethics course with mixed methods of teaching such as didactic lectures, case studies, class discussions/debates, team-based learning and presentations among others in their curricula. This innovative strategy is to vouch for a minimum level of pharmacy 
Table 1: NUC approved forensic pharmacy and pharmacy ethics syllabus for pharmD programme Course descriptions ( 2 credit unit)

- $\quad$ History of pharmacy in Nigeria

- $\quad$ Ethics of pharmacy profession in Nigeria

- Ethics and good business practice

- $\quad$ Laws related to the National Agency for Food and Drug Administration and Control (NAFDAC), National Drug Law Enforcement Agency (NDLEA), Standard Organization of Nigeria (SON), Pharmacists Council of Nigeria (PCN), WHO/FAO Codex Allimentarium Commission, United Nations Narcotic Commission, Federal Environmental Protection Agency (FEPA), etc;

- Food, drug and cosmetics laws including regulation, inspection, registration, advertising, manufacture, and sale/distribution.

- $\quad$ Poison, dangerous drugs and pharmacy Acts; Essential Drugs List (EDL); Fake and counterfeit drug laws; Consumer protection council law

- Policy and Legal Framework - Legal procedure; Information service; Intellectual property rights and patenting of inventions; Risk and insurance; Legal aspects of employment; Taxation

- All other relevant laws related to the practice of pharmacy including those of the Pharmacists Disciplinary Committee and Assessors rules, Pharmacists registration rules, Dispensing of Drugs, Patent and Proprietary Medicines, etc.

- Legislation on animal health products.

- $\quad$ National Health Insurance Scheme (NHIS) and other health policies, and National Drug Policy.

Table 2: Pharmacy ethics syllabus of the College of Pharmacy, University of Texas, US for the PharmD programme Course description

\section{Ethics and values in pharmacy}

- Introduction to ethics, values, and moral reasoning

- Models for ethical problem solving

- Model for ethical problem solving

- Values in health and illness

- Sources of moral judgments

- Conceptual framework review - elements, principles, and processes

- Models for ethical problem solving

- Team case presentations

- The "Georgetown Mantra" - ethical principles

- Interprofessional case discussion panel

Ethical principles in pharmacy ethics

- Topic clarification: beneficience, non-maleficience, autonomy, and justice

- Team case presentations

- $\quad$ Principle application cases: sources of moral judgments - role of professional codes

- Team case presentations

- Interprofessional case discussion panel

- $\quad$ Professional duties of practitioners - applying principles to patient situations

- Team case presentations

Honesty, truth telling, and avoidance of killing

- Dealing honestly with patients

- $\quad$ Ethical issues in pain management

- Interprofessional case discussion panel

Sensitive patient scenarios - application of ethical principles and decision-making models

- Abortion, sterilization, and contraception

- Mental health issues

- Right of refusal

- Research ethics

- $\quad$ Principle application cases: avoidance of killing

- Principle application cases: application of ethical principles in sensitive patient situations

- Right of refusal and patient autonomy

- Team case presentations 
ethics knowledge, competencies, skills and, even the character of their graduates. Hence, the overall goals of the pharmacy ethics education are to endow students with a set of cognitive and behavioural skills for ethical reasoning that will allow them to recognize ethical dilemmas in pharmacy practiceand research, and equip them to make appropriate, justifiable socio-culturally sensitive decisions to those dilemmas.

Against this background, this paper proposes a curricular modification with respect to pharmacy ethics to reflect the current reality of global best patient-centred pharmacy practice in Nigeria. Syllabus content, teaching and assessment methods should be reconsidered and developed to foster deeplevel learning, and achievement of the objectives of this course. In view of this, a model pharmacy ethics syllabus can be adapted from that of the college of pharmacy at University of Texas (Table 2).

Unlike the current Nigerian model, the proposed model is more patient-centred because it explores ethical issues pharmacists face as a member of the healthcare team and provide a framework for addressing ethical dilemmas. This is so because the proposed model will help students to identify the importance of morality and ethics in healthcare and their role in the provision of pharmacist-directed patient care. It will demonstrate competency in the application of bioethical principles to patients' situations. Also, it will equip students with skills required to apply appropriate decision-making strategies in providing care for patients. Lastly, it has the potential to build interprofessional collaborative practice in developing effective interpersonal communication skills required of a pharmacist and reap the benefits of discussing ethical dilemmas with other healthcare team members.
Conclusion : Today, pharmacy ethics contents of the Nigerian pharmacy education curriculum of is grossly inadequate and the teaching method too didactic to adequately prepare future pharmacists for the more challenging patient-centred roles with practice environment full of ethical dilemmas. Curriculum design and methods of teaching are critical to renewal and progress in any profession. Therefore, there is an urgent need to develop an enriched standalone pharmacy ethics course that will include all relevant ethical issues encountered in routine clinical pharmacy practice in Nigeria. Finally, varieties of teaching methods such as classroom discussions/debates, case studies, and teambased learning approaches should be adopted for effective delivery of this course to the students.

\section{References:}

1. Tekiner H. Why Teach Pharmacy Ethics Through Literary Fiction? World J Pharm Sci. 2017; 5(6):203-206.

2. Buerki RA, Vottero LD. Ethical Responsibility in Pharmacy Practice. 2nd ed. Madison: American Institute of the History of Pharmacy. 2002.

3. Wingfield J, Bissell P, Anderson C. The Scope of Pharmacy Ethics: Ann Evaluation of the International Research Literature, 1990-2002. Soc Sci Med. 2004; 58(12):2383-2396.

4. Hasan S. Teaching Ethics to Pharmacy Students Using a Team-Based Learning Approach. Pharmacy Education. 2011; 11(1):99-106.

5. Benchmark Minimum Academic Standards for Undergraduate Programmes in Nigerian Universities, Pharmaceutical Sciences. Nigerian University Commission. 2018.

6. Undergraduate and Postgraduate Programmes Prospectus 2000/2001 Academic Session, Faculty of Pharmacy, University of Benin, Benin City, Edo State, Seevon Prints, Nigeria, 2001 pp. 49-50. 
7. Fadare JO, Desalu OO, Jemilohun AC, Babatunde OA. Knowledge of medical ethics among Nigerian medical doctors. Niger Med J. 2012; 53(4):226-230.

8. Accreditation Council for Pharmacy Education. Accreditation (ACPE) Standards 2016 Accreditation Council for Pharmacy Education. Available from: https://www.acpeaccredit.org/pdf/Standards2016FINAL.pdf. Accessed July 11, 2018.
Author contribution: Author conceive the idea, done literature review and wrote the manuscript and check the manuscript meticulously.

Conflict of interest: The author declares no conflict of interest. 